\title{
Effect of varying total mixed ration particle size on rumen digesta and fecal particle size and digestibility in lactating dairy cows ${ }^{1}$
}

\author{
D. D. Maulfair, ${ }^{\star}$ M. Fustini, $\dagger$ and A. J. Heinrichs ${ }^{\star 2}$ \\ *Department of Dairy and Animal Science, The Pennsylvania State University, University Park 16802 \\ †Facolta' di Medicina Veterinaria, Universita' di Bologna, Bologna 40064, Italy
}

\begin{abstract}
The objective of this experiment was to evaluate the effects of feeding rations of different particle sizes on rumen digesta and fecal matter particle size. Four rumencannulated, multiparous, Holstein cows $(104 \pm 15 \mathrm{~d}$ in milk) were randomly assigned to treatments in a $4 \times 4$ Latin square design. The diets consisted of $29.4 \%$ corn silage, $22.9 \%$ ground corn, $17.6 \%$ alfalfa haylage, and $11.8 \%$ dry grass hay [20\% of forage dry matter (DM)] on a DM basis. Dry grass hay was chopped to 4 different lengths to vary the total mixed ration (TMR) particle size. Geometric mean particle sizes of the rations were $4.46,5.10,5.32$, and $5.84 \mathrm{~mm}$ for short, medium, long, and extra long diets, respectively. The ration affected rumen digesta particle size for particles $\geq 3.35 \mathrm{~mm}$, and had no effect on distribution of particles $<3.35 \mathrm{~mm}$. All rumen digesta particle size fractions varied by time after feeding, with soluble particle fractions increasing immediately after feeding and 0.15, 0.6, and 1.18-mm particle size fractions decreasing slightly after feeding. Particle fractions $>1.18 \mathrm{~mm}$ had ration by time interactions. Fecal neutral detergent fiber (NDF) and indigestible NDF concentrations decreased with increasing TMR particle size. Fecal particle size expressed as total geometric mean particle length followed this same tendency. Fecal particle size, expressed as retained geometric mean particle length, averaged $1.13 \mathrm{~mm}$ with more than $36 \%$ of particles being larger than $1.18 \mathrm{~mm}$. All fecal nutrient concentrations measured were significantly affected by time after feeding, with NDF and indigestible NDF increasing after feeding and peaking at about $12 \mathrm{~h}$ later and then decreasing to preprandial levels. Starch concentrations were determined to have the opposite effect. Additionally, apparent digestibility of diet nutrients was analyzed and DM digestibility tended to decrease with increasing TMR particle size, whereas

\footnotetext{
Received August 11, 2010.

Accepted March 13, 2011.

${ }^{1}$ This research was a component of NC-1042, Management Systems

${ }^{2}$ Corresponding author: ajh@psu.edu
} to Improve the Economic and Environmental Sustainability of Dairy Enterprises.
\end{abstract}

other nutrient digestibilities were not different among rations. These results show that the critical size for increased resistance to rumen escape is larger than 1.18 $\mathrm{mm}$ and this critical size is constant throughout the day. This study also concludes that, when using average quality grass hay to provide the range of particle sizes fed, DM digestibility tends to decrease with increasing ration particle size.

Key words: digestibility, particle size, rumen escape

\section{INTRODUCTION}

The sieve size $1.18 \mathrm{~mm}$ has been widely used as the size in which feed particles retained on or above are considered physically effective for dairy cows. This number originated from research of Evans et al. (1973) and Poppi et al. $(1980,1981)$, where resistance of particles leaving the rumen of cattle and sheep was measured. It was determined that $1.18 \mathrm{~mm}$ was a threshold particle size for both cattle and sheep for greatly increased resistance to particles leaving the rumen and $<5 \%$ of fecal particles are generally retained on a 1.18mm sieve (Poppi et al., 1980, 1981). It should be noted that a wet-sieving technique was used in these studies to measure particle size and this procedure is very different from the dry vertical sieving procedure used by Mertens (1997) to develop the physical effectiveness factor of feeds (using particles retained on a 1.18-mm sieve) that is used by some ration formulation software today. Therefore, it should not be assumed that these 2 different sieving methods will produce similar results. Some researchers have suggested that the critical particle size for rumen escape in dairy cattle may be larger than $1.18 \mathrm{~mm}$ (Yang et al., 2001; Oshita et al., 2004); however, determining this has proven difficult. Also, little is known about whether diet particle size or time after feeding affects this critical particle size for passage from the rumen.

Some controversy exists regarding the effect of ration particle size on DM digestibility (DMD). Kononoff and Heinrichs (2003a) and Yang and Beauchemin (2005) reported that increasing ration particle size increased DMD; however, Kononoff and Heinrichs (2003b) ob- 
served that increasing ration particle size decreased DMD. In addition, several studies reported no effect of ration particle size on DMD (Krause et al., 2002; Yang and Beauchemin, 2006, 2007). Clearly this effect is variable, based on other aspects of the diet or management. Therefore, the objective of this experiment was to study effects of varying TMR particle size on rumen digesta and fecal particle size in lactating dairy cows to determine the critical size for particles leaving the rumen and if rumen and fecal particle size change throughout the day and according to diet particle size.

\section{MATERIALS AND METHODS}

\section{Diets, Cows, and Experimental Design}

Cows used in this research were cared for and maintained according to a protocol approved by The Pennsylvania State University Institutional Animal Care and Use Committee. Four lactating, multiparous, rumen-cannulated Holstein cows, averaging $104 \pm 15$ DIM, weighing $659 \pm 88 \mathrm{~kg}$, and with parity of 2.25 \pm 0.50 (mean $\pm \mathrm{SD}$ ) were randomly assigned to treatments in a $4 \times 4$ Latin square design. Periods were 21 $\mathrm{d}$ in length, with a 13-d adaptation period, followed by an 8-d collection period. During each of the 4 periods, cows were fed 1 of 4 rations that contained identical feed ingredients and proportions but varied in the length of dry grass hay included in the ration. Ingredients and their percentage of ration DM were corn silage (29.4), ground corn (22.9), haylage (17.6), grass hay (11.8), roasted soybeans (6.7), canola meal (5.7), heat-treated soybean meal (3.2), mineral/vitamin mix (2.4), and salt (0.3).

More detailed information regarding diets was reported by Maulfair et al. (2010). Rations were designated as short $(\mathbf{S})$, medium $(\mathbf{M})$, long $(\mathbf{L})$, and extra long (XL). Animals were housed in individual stalls, milked 2 times/d at 0700 and $1900 \mathrm{~h}$, and fed 1 time/d at approximately $0730 \mathrm{~h}$ for ad libitum consumption with $12 \%$ refusal to allow maximum opportunity to sort the ration. Feed was pushed up 3 times/d at 1230, 1730 , and $2400 \mathrm{~h}$. All rations were balanced to meet or exceed NRC (2001) requirements, and water was available ad libitum.

\section{Rumen Sampling}

On d 15 of each period, ruminal contents were collected from dorsal, ventral, cranial, caudal, and medial areas of the rumen at $0.0,1.5,3.5,5.5,8.5,11.5$, 14.5, 18.0, 21.5, and $24.5 \mathrm{~h}$ after feeding (Kononoff et al., 2003b). Collected digesta was mixed thoroughly, sampled, and filtered through 4 layers of cheesecloth.
Solid portions of digesta samples retained on cheesecloth were stored at $-20^{\circ} \mathrm{C}$ for later determination of particle size distribution via the wet-sieving technique of Maulfair and Heinrichs (2010). Maulfair and Heinrichs (2010) determined that squeezing rumen digesta through cheesecloth before wet sieving had no effect on particle size distribution of particles $>0.15 \mathrm{~mm}$ but decreased the amount of soluble DM contained in the sample. Representative samples (approximately $30 \mathrm{~g}$ ) were mixed in $1 \mathrm{~L}$ of water and soaked for $10 \mathrm{~min}$. Samples were then placed on a series of stacked sieves (sizes 0.15, 0.6, 1.18, 3.35, 6.7, $9.5 \mathrm{~mm}$; VWR, Arlington Heights, IL) contained in a Retsch AS 200 Control sieve shaker (Retsch GmbH, Haan, Germany) and sieved in duplicate. Samples were sieved for $10 \mathrm{~min}$ at $2.5-\mathrm{mm}$ amplitude with the sprayer ring located between 3.35and $1.18-\mathrm{mm}$ screens and cold water flow rate at approximately 1.5 to $2.0 \mathrm{~L} / \mathrm{min}$ to ensure particles were separated thoroughly. Sieve contents were rinsed into a funnel with rumen in situ bags $(5 \times 10 \mathrm{~cm}, 53 \mu \mathrm{m}$ pore size; Ankom, Macedon, NY) attached to the stem to collect the sample. Bags were then dried in a forced-air oven at $55^{\circ} \mathrm{C}$ for $24 \mathrm{~h}$ and weighed to determine DM retained on each sieve. A portion of each sample was also dried at $55^{\circ} \mathrm{C}$ for $24 \mathrm{~h}$ in a forced-air oven without sieving to determine DM content of the original sample. The soluble fraction of the sample was calculated as the DM lost during sieving and drying. Data were analyzed using each particle fraction as a percentage of DM retained on $\geq 0.15$-mm screen (retained) and also as the percentage of DM of the entire sample sieved (total).

\section{Fecal Sampling}

Fecal sampling occurred at the same time points as rumen sampling (d 15 at $0.0,1.5,3.5,5.5,8.5,11.5,14.5$, 18.0, 21.5, and $24.5 \mathrm{~h}$ after feeding) via grab samples from the rectum. Samples were stored at $-20^{\circ} \mathrm{C}$ until later determination of particle size distribution and concentration of DM, NDF, indigestible NDF (INDF), starch, and ash. The particle size of subsamples was determined using the same wet-sieving technique used for rumen digesta, with the exception of eliminating the top screen $(9.5 \mathrm{~mm})$. The geometric mean particle length $\left(\mathbf{X}_{\mathrm{gm}}\right)$ and standard deviation of particle length $\left(\mathrm{S}_{\mathrm{gm}}\right)$ were calculated according to the American Society of Agricultural and Biological Engineers (ASABE, 2007) procedure. The geometric mean particle length was calculated using 2 procedures; the first, retained $\mathrm{X}_{\mathrm{gm}}\left(\mathbf{X}_{\mathrm{gm}} \mathbf{R e t}\right)$, only considered particles retained on the $0.15-\mathrm{mm}$ screen or larger; the second procedure, total $\mathrm{X}_{\mathrm{gm}}\left(\mathbf{X}_{\mathrm{gm}} \mathbf{T o t}\right)$, considered all particle fractions, including the soluble fraction that passed through the bottom screen $(0.15 \mathrm{~mm})$. The mean particle length of 
the soluble fraction was assumed to be $0.106 \mathrm{~mm}$, which is half of the diagonal screen diameter $(0.212 \mathrm{~mm})$ of the bottom screen; this is the assumption that ASABE (2007) uses for mean length of particles on the pan. Subsamples were also placed in a forced-air oven at $55^{\circ} \mathrm{C}$ for $48 \mathrm{~h}$ to determine $\mathrm{DM}$ content and were then ground (1-mm screen; Wiley Mill; Arthur H. Thomas Co., Inc., Swedesboro, NJ) to determine NDF content using heat-stable $\alpha$-amylase and $\mathrm{Na}_{2} \mathrm{SO}_{3}$ according to Van Soest et al. (1991) and ground (0.5-mm screen; Wiley Mill; Arthur H. Thomas Co., Inc.) to analyze starch, using a modified procedure from Knudsen (1997; modification included $150 \mathrm{mg}$ of sample, 45 units of amyloglucosidase, and analysis of released glucose monomers with procedure no. 1075; Stanbio Laboratory, Inc., Boerne, TX). For INDF determination, subsamples were enclosed in F57 filter bags (Ankom Technology) in sextuplicate, then incubated in the rumen of 2 cows (each cow incubated 3 bags of each sample) for $12 \mathrm{~d}$. After removal from the rumen, bags were rinsed in cold water by hand until water was almost clear. Bags were then dried in a forced-air oven at $55^{\circ} \mathrm{C}$ for 48 $\mathrm{h}$ and later processed using the same procedure as that used for NDF determination. Ash was determined by combustion at $600^{\circ} \mathrm{C}$ for $6 \mathrm{~h}$ (AOAC, 1990).

\section{Digestibility}

Dry matter intakes were recorded daily and feed bunk contents were sampled at 0 and $24 \mathrm{~h}$ after feeding on d 21 and 22 and were analyzed for DM, NDF, INDF, and starch, using identical procedures to those of fecal samples. Intakes of NDF, INDF, and starch were determined by subtracting the amount of each in refusals (refused TMR weight $\times$ refused TMR concentration) from the amount of each fed (fed TMR weight $\times$ fed TMR concentration). Fecal output was calculated by dividing intake of INDF by INDF concentration (24.5-h weighted mean) in feces. Because intake is based on a 24-h period and fecal output is based on a $24.5-\mathrm{h}$ period, it must be assumed that the 30-min difference will not significantly affect the results. Apparent digestibilities for all parameters were calculated by the following formula: [intake - (24.5-h weighted mean concentration in feces $\times$ fecal output) $] \div$ intake.

\section{Statistical Analyses}

Statistical analysis was conducted using the PROC MIXED of SAS (SAS Institute, 2006). Dependent variables were analyzed as a $4 \times 4$ Latin square design. All denominator degrees of freedom for $F$-tests were calculated according to Kenward and Roger (1997) and repeated measurements for rumen and fecal samples were analyzed using the first-order autoregressive covariance structure (Littell et al., 1998), as well as terms for time and interaction of treatment by time. Because of unequally spaced rumen and fecal sampling, weighted mean daily concentrations and proportions were determined by calculating the area under the response curve according to the trapezoidal rule (Shipley and Clark, 1972). Data were analyzed for orthogonal contrasts using the fed TMR $\mathrm{X}_{\mathrm{gm}}$ that was corrected for unequal spacing according to Robson (1959). All data are presented as least squares means; treatment effects are considered significant when $P<0.05$ and a trend when $P<0.10$.

\section{RESULTS AND DISCUSSION}

\section{Chemical Composition and Particle Size Distribution}

Chemical composition, particle size distribution, and $\mathrm{X}_{\mathrm{gm}}$ of forages included in the rations are shown in Table 1. The $M$ hay had lower ADF and NDF and higher NFC values than other hay lengths; this was probably because of individual bale variation. Although all bales were from the same field and cutting, each length of hay was composed of different bales. These differences, however, did not affect TMR chemical composition because the $0.86 \%$ expected change in TMR NDF concentration was probably masked by sampling and laboratory error (Table 2). Particle size was determined with the ASABE forage particle separator because particle length of some diets was so great that the Penn State Particle Separator (PSPS; University Park, PA) did not adequately separate samples and small particles were improperly retained on the top screen. The PSPS particle fractions and their approximate equivalent ASABE separator screens are top (26.9 $+18.0 \mathrm{~mm})$, middle $(8.98 \mathrm{~mm})$, lower $(5.61+1.61$ $\mathrm{mm}$ ), and pan (pan). Particle size distribution of the fed TMR varied greatly among treatments, but chemical compositions were similar (Table 2). More detailed information regarding forages and diets was reported by Maulfair et al. (2010).

\section{Rumen Particle Size}

No differences existed in study conclusions between analysis of particle fractions as percentage of retained or total DM; therefore, discussion and graphs of rumen digesta will be based on total DM. Particles that passed through the $3.35-\mathrm{mm}$ screen were affected by time after feeding but not by ration; these particle fractions were $1.18,0.6,0.15 \mathrm{~mm}$, and soluble, whereas particles retained on 9.5-, 6.7-, and 3.35-mm screens were affected by both time and ration. These findings 
Table 1. Chemical composition and particle size distributions determined with the American Society of Agricultural and Biological Engineers (ASABE) particle separator for corn silage, alfalfa haylage, and short (S), medium (M), long (L), or extra long (XL) grass hay

\begin{tabular}{|c|c|c|c|c|c|c|c|c|}
\hline Item & $\begin{array}{l}\text { Corn } \\
\text { silage }\end{array}$ & $\begin{array}{c}\text { Alfalfa } \\
\text { haylage }\end{array}$ & \multicolumn{6}{|c|}{ Grass hay } \\
\hline \multicolumn{9}{|c|}{ Particle size, as-fed $\%$ retained ${ }^{1}$} \\
\hline $18.0 \mathrm{~mm}$ & 3.4 & 6.7 & $13.1^{\mathrm{a}}$ & $12.9^{\mathrm{a}}$ & $11.5^{\mathrm{a}}$ & $6.8^{\mathrm{b}}$ & 1.38 & 0.04 \\
\hline $8.98 \mathrm{~mm}$ & 53.0 & 32.8 & $17.8^{\mathrm{a}}$ & $15.7^{\mathrm{a}}$ & $10.4^{\mathrm{b}}$ & $5.3^{\mathrm{c}}$ & 1.38 & $<0.01$ \\
\hline $5.61 \mathrm{~mm}$ & 29.1 & 27.3 & $20.1^{\mathrm{a}}$ & $9.6^{\mathrm{b}}$ & $6.2^{\mathrm{c}}$ & $3.7^{\mathrm{d}}$ & 0.65 & $<0.01$ \\
\hline $\mathrm{X}_{\mathrm{gm}},{ }^{2} \mathrm{~mm}$ & 9.0 & 7.0 & $5.2^{\mathrm{C}}$ & $14.6^{\mathrm{c}}$ & $38.0^{\mathrm{b}}$ & $65.4^{\mathrm{a}}$ & 3.67 & $<0.01$ \\
\hline $\mathrm{S}_{\mathrm{gm}}, 3 \mathrm{~mm}$ & 1.8 & 2.5 & $3.5^{\mathrm{c}}$ & $4.9^{\mathrm{a}}$ & $4.2^{\mathrm{b}}$ & $3.4^{\mathrm{c}}$ & 0.18 & $<0.01$ \\
\hline \multicolumn{9}{|c|}{ Composition, \% of DM } \\
\hline $\mathrm{DM}, \%$ & 34.5 & 43.5 & $90.5^{\mathrm{a}}$ & $89.8^{\mathrm{ab}}$ & $90.1^{\mathrm{ab}}$ & $89.4^{\mathrm{b}}$ & 0.28 & 0.14 \\
\hline $\mathrm{CP}$ & 7.2 & 22.6 & 8.2 & 10.5 & 10.5 & 8.5 & - & - \\
\hline $\mathrm{ADF}$ & 23.6 & 29.9 & 38.6 & 33.8 & 38.4 & 39.9 & - & - \\
\hline NDF & 37.0 & 34.5 & 66.6 & 59.7 & 67.1 & 67.3 & - & - \\
\hline
\end{tabular}

$\overline{\mathrm{a}-\mathrm{d}}$ Means within a row with different superscripts differ $(P<0.05)$.

${ }^{1}$ Approximate equivalency to Penn State Particle Separator (PSPS; University Park, PA): top sieve $(26.9+18.0 \mathrm{~mm})$, middle sieve (8.98 mm), lower sieve $(5.61+1.65 \mathrm{~mm})$, and pan $(\operatorname{pan})$.

${ }^{2}$ Geometric mean particle length determined by ASABE (2007).

${ }^{3}$ Particle length standard deviation determined by ASABE (2007).

${ }^{4}$ Physically effective $\mathrm{NDF}_{8.0}=\%$ of particles $>8.98 \mathrm{~mm} \times \mathrm{NDF}$ of whole sample (similar to top 2 sieves of PSPS; Kononoff et al., 2003a).

${ }^{5}$ Physically effective $\mathrm{NDF}_{1.18}=\%$ of particles $>1.65 \mathrm{~mm} \times \mathrm{NDF}$ of whole sample (similar to top 3 sieves in PSPS; Kononoff et al., 2003a).

${ }^{6}$ As described by NRC (2001).

Table 2. Chemical composition and particle size distributions determined with the American Society of Agricultural and Biological Engineers (ASABE) particle separator for TMR containing short (S), medium (M), long (L), or extra long (XL) grass hay

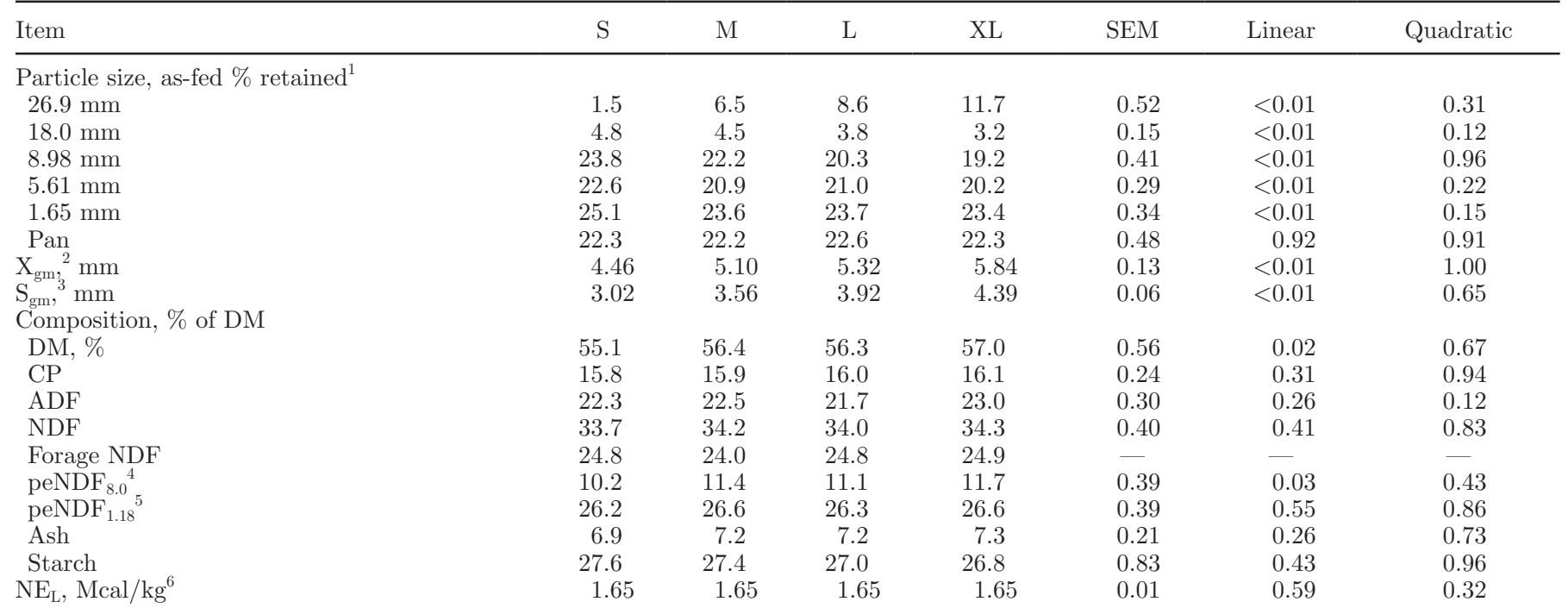

${ }^{1}$ Approximate equivalency to Penn State Particle Separator (PSPS; University Park, PA): top sieve (26.9 + $\left.18.0 \mathrm{~mm}\right)$, middle sieve (8.98 mm), lower sieve $(5.61+1.65 \mathrm{~mm})$, and pan (pan).

${ }^{2}$ Geometric mean particle length determined by ASABE (2007).

${ }^{3}$ Particle length standard deviation determined by ASABE (2007).

${ }^{4}$ Physically effective $\mathrm{NDF}_{8.0}=\%$ of particles $>8.98 \mathrm{~mm} \times \mathrm{NDF}$ of whole sample (similar to top 2 sieves of PSPS) (Kononoff et al., 2003a).

${ }^{5}$ Physically effective $\mathrm{NDF}_{1.18}=\%$ of particles $>1.65 \mathrm{~mm} \times \mathrm{NDF}$ of whole sample (similar to top 3 sieves in PSPS) (Kononoff et al., 2003a).

${ }^{6}$ As described by NRC (2001). 
are similar to those of Kononoff and Heinrichs (2003a), who found that rumen digesta particles retained on $13.2-$ and $6.7-\mathrm{mm}$ sieves increased with increasing ration particle size, whereas particles retained on 0.6- and $0.15-\mathrm{mm}$ sieves were not affected by ration particle size. However, Kononoff and Heinrichs (2003a) determined that particles retained on the 1.18-mm sieve decreased with increasing ration particle size, in contrast to the present study. This contradiction may be caused by differences in forages used in these studies; the present study used corn silage, alfalfa haylage, and dry grass hay, whereas Kononoff and Heinrichs (2003a) used only corn silage. Evans et al. (1973) also determined that coarse particles retained on the largest screen $(2.4 \mathrm{~mm})$ responded to effects of time and feeding and smaller particles had less response. These particle fractions, and additionally the soluble DM-to-retained DM ratio, are shown in Figure 1 and expressed as the mean of the 4 treatments. Particles in the soluble fraction and the soluble DM-to-retained DM ratio markedly increased after feeding, remained elevated, and began to decrease slowly at $11.5 \mathrm{~h}$ after feeding, eventually returning to pre-prandial levels just before the next feeding. Particles retained on the $0.15-\mathrm{mm}$ screen exhibited the opposite effect: they decreased after feeding, remained lowered, and began to slowly increase at about $11.5 \mathrm{~h}$ after feeding to pre-prandial levels. Particles retained on 1.18- and $0.6-\mathrm{mm}$ screens had less substantial changes compared with the other particle fractions. These fractions followed a similar pattern as the 0.15$\mathrm{mm}$ fraction, as they decreased after feeding and began to slowly increase at about $11.5 \mathrm{~h}$ after feeding. Figure 2 shows that the $6.7-\mathrm{mm}$ particle fraction was least abundant for all rations. The most abundant fraction for $\mathrm{S}$ was $3.35 \mathrm{~mm}$, for $\mathrm{L}$ and XL was $9.5 \mathrm{~mm}$, and for $\mathrm{M}$ alternated between 3.35 and $9.5 \mathrm{~mm}$. The $\mathrm{M}$ diet started with $3.35 \mathrm{~mm}$ being most abundant; by $8.5 \mathrm{~h}$ after feeding, $9.5 \mathrm{~mm}$ became most abundant; finally, at $24.5 \mathrm{~h}$ after feeding, $3.35 \mathrm{~mm}$ was again the most abundant particle fraction. Ration by time interactions existed, as the 9.5-mm fraction increased after feeding in $\mathrm{S}$ and $\mathrm{L}$ diets, whereas it decreased in $\mathrm{M}$ and $\mathrm{XL}$ diets. The $3.35-\mathrm{mm}$ particle fraction increased in XL diets, decreased in $\mathrm{S}$ and $\mathrm{L}$ diets, and maintained its level in $\mathrm{M}$ diets. It seems that the $9.5-\mathrm{mm}$ and 3.35 $\mathrm{mm}$ particle fractions acted inversely of each other after feeding. The $6.7-\mathrm{mm}$ particle fraction did not have substantial changes over time after feeding.

\section{Fecal Particle Size and Composition}

The weighted means for fecal concentrations of NDF, INDF, starch, ash, and DM are shown in Table 3. The weighted mean represents the average value over the course of the day even though sampling time points were not equally spaced. A significant linear contrast was observed for fecal NDF concentrations to decrease (from 50.7 to $47.2 \%$ ) with increasing TMR particle size (from $\mathrm{S}$ to $\mathrm{XL}$ ), even though NDF intake was not different across treatments (Maulfair et al., 2010). Fecal INDF concentration also followed this tendency, decreasing from 30.0 to $27.4 \%$ with increasing TMR particle size. No differences in weighted means for starch, ash, and DM concentrations were found. When determining fecal particle size distribution, no particles were retained on the $6.7-\mathrm{mm}$ screen. Fecal particle size was expressed as $\mathrm{X}_{\mathrm{gm}}$ using 2 different procedures. The $\mathrm{X}_{\mathrm{gm}}$ Ret procedure (using only particles retained on $\geq 0.15$-mm screens) did not result in any differences among rations for weighted means, and $\mathrm{X}_{\mathrm{gm}}$ of all rations averaged $1.13 \mathrm{~mm}$. These values agree with the results of Kononoff and Heinrichs (2003a,b), who reported that fecal $\mathrm{X}_{\mathrm{gm}}$ averaged 1.13 and $1.03 \mathrm{~mm}$, respectively, and did not change based on ration particle size. These fecal particle size data are lower than those reported by Yang et al. (2001), which averaged $1.86 \mathrm{~mm}$ and also did not differ in response to ration particle size. The $\mathrm{X}_{\mathrm{gm}}$ Tot procedure (using all particle fractions) had much lower values than $\mathrm{X}_{\mathrm{gm}}$ Ret and had a significant linear contrast for fecal $\mathrm{X}_{\mathrm{gm}}$ to decrease with increasing TMR particle size, decreasing from 0.33 to $0.31 \mathrm{~mm}$ for S to XL, respectively. This effect was caused by the increasing proportion of the soluble DM fraction with increasing ration particle size, whereas all other particle fractions exhibited no effect of ration (Table 4). One possible explanation for increased soluble DM in feces is that chewing minutes per kilogram of DMI increased

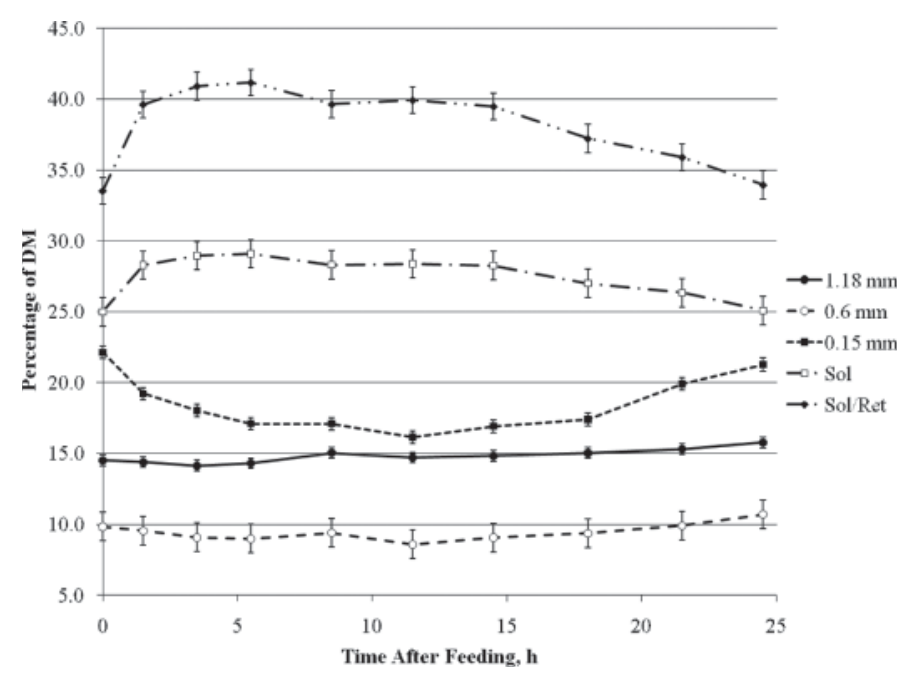

Figure 1. Mean rumen digesta particles of all treatments retained on 1.18-, 0.6-, 0.15-mm screens, soluble fraction (Sol), and soluble DMto-retained DM ratio (Sol/Ret) throughout the day. 

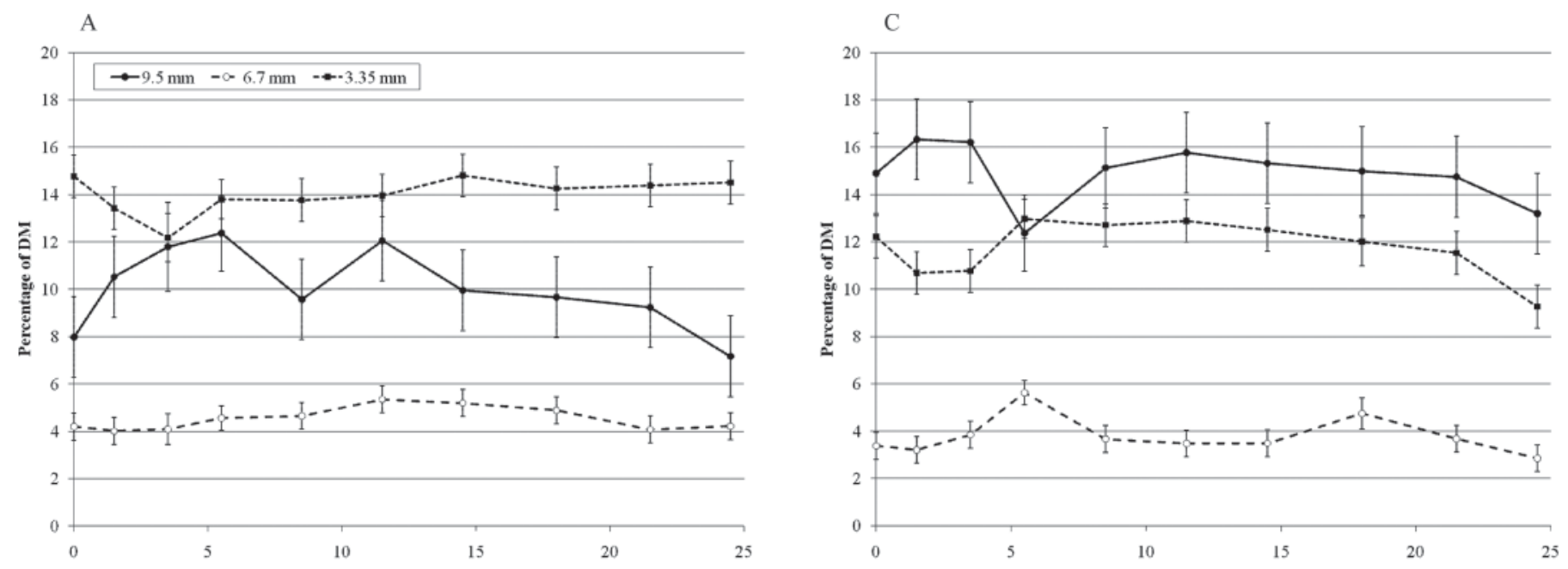

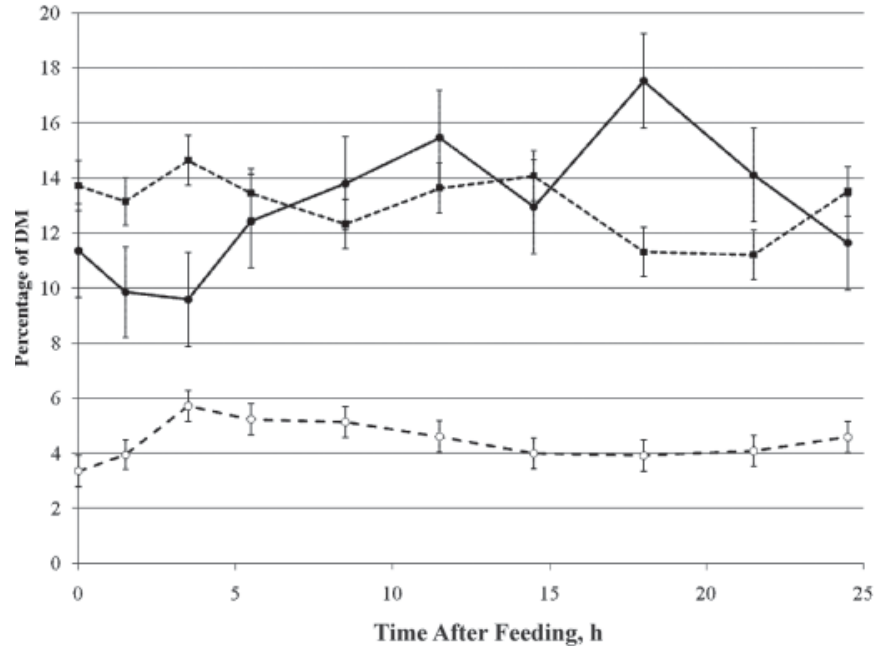

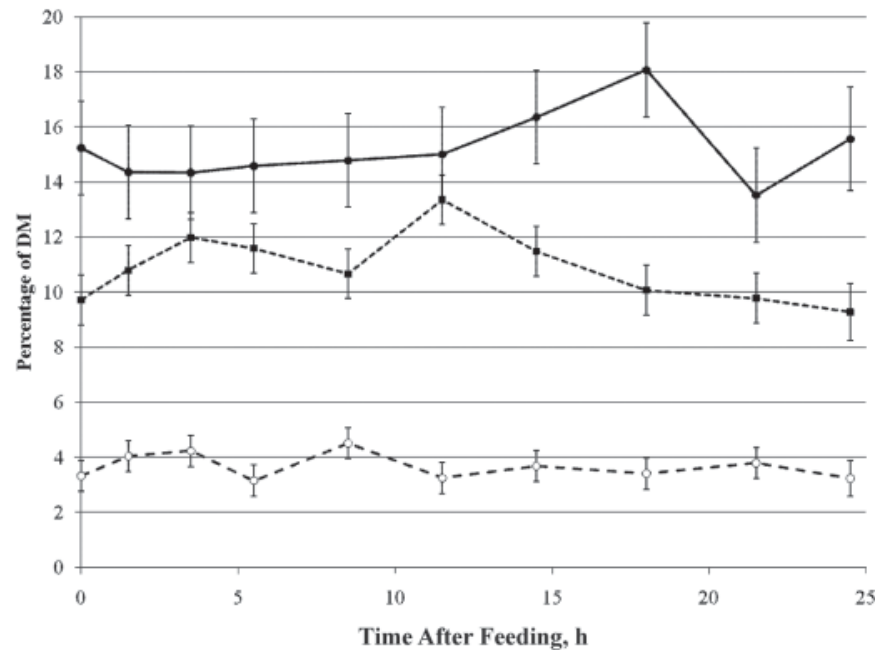

Figure 2. Effect of feeding short (A), medium (B), long (C), and extra long (D) TMR on rumen digesta particles retained on 9.5-, 6.7-, and $3.35-\mathrm{mm}$ screens throughout the day.

with TMR of larger particle size (Maulfair et al., 2010), possibly increasing saliva secretion, therefore increasing liquid passing out of the rumen and causing a greater proportion of particles $<0.15 \mathrm{~mm}$ to leave the rumen (Owens and Isaacson, 1977). Another possible cause of increased soluble DM in feces is increased hind-gut fermentation, leading to higher numbers of bacteria, which would be included in the soluble fraction. The fecal particle distribution resulted in approximately $16 \%$ of particles $>3.35 \mathrm{~mm}$ and $37 \%>1.18 \mathrm{~mm}$ as a proportion of DM retained on the 0.15 - $\mathrm{mm}$ sieve. The distribution had approximately $7 \%$ of particles $>3.35 \mathrm{~mm}$ and $17 \%$ $>1.18 \mathrm{~mm}$ as a proportion of total sample DM. These results are similar to those of Kononoff and Heinrichs (2003a,b), who reported that 48 and $46 \%$, respectively, of fecal particles were $>1.18 \mathrm{~mm}$ as a proportion of DM retained on a $0.15-\mathrm{mm}$ sieve; however, they are much higher than those observed by Poppi et al. (1981, 1985), where $<5 \%$ of particles were $>1.18 \mathrm{~mm}$ as a proportion of total sample DM in mature steers fed exclusively forage. The reasons for the 3 - to 4 -fold increase in particles $>1.18 \mathrm{~mm}$ escaping the rumen are probably because of large differences in DMI and passage rate of high-producing dairy cows compared with steers being fed a maintenance diet. When fecal nutrients were analyzed over time it was determined that NDF, INDF, starch, ash, and DM concentrations were all affected by time after feeding (Figure 3). In all rations, both NDF and INDF concentrations increased after feeding to a peak at about $11.5 \mathrm{~h}$ after feeding, and then decreased to pre-prandial levels. Fecal starch concentrations, however, exhibited the opposite tendency, with starch 
Table 3. Effect of feeding TMR containing short (S), medium (M), long (L), or extra long (XL) grass hay on daily weighted means of fecal NDF, indigestible NDF (INDF), starch, ash, DM, and geometric mean particle length $\left(\mathrm{X}_{\mathrm{gm}}\right)$

\begin{tabular}{lccccccc}
\hline $\begin{array}{l}\text { Item, } \\
\text { \% of DM }\end{array}$ & $\mathrm{S}$ & $\mathrm{M}$ & $\mathrm{L}$ & $\mathrm{XL}$ & $\mathrm{SEM}$ & Linear & Quadratic \\
\hline NDF & 50.7 & 48.2 & 47.2 & 47.2 & 0.98 & 0.03 & 0.28 \\
$\mathrm{INDF}$ & 30.0 & 29.6 & 28.6 & 27.4 & 0.99 & 0.01 & 0.40 \\
Starch & 3.8 & 2.9 & 4.0 & 3.9 & 0.57 & 0.69 & 0.39 \\
Ash & 9.3 & 9.3 & 9.3 & 9.0 & 0.28 & 0.47 & 0.56 \\
DM, \% & 15.3 & 15.5 & 15.8 & 15.9 & 0.39 & 0.19 & 0.97 \\
X $_{\text {gm }}$ Ret $^{2}$ & 1.13 & 1.16 & 1.11 & 1.10 & 0.05 & 0.41 & 0.42 \\
S $_{\text {gm }}$ Ret $^{4}$ & 1.28 & 1.29 & 1.27 & 1.28 & 0.01 & 0.50 & 0.43 \\
X $_{\text {gm }}$ Tot $^{4}$ & 0.33 & 0.32 & 0.30 & 0.31 & 0.01 & 0.03 & 0.64 \\
S $_{\text {gm }}$ Tot $^{5}$ & 1.52 & 1.53 & 1.49 & 1.50 & 0.02 & 0.13 & 0.79 \\
\hline
\end{tabular}

${ }^{1}$ Weighted means determined by calculating area under the response curve according to the trapezoidal rule (Shipley and Clark, 1972).

${ }^{2}$ Geometric mean particle length determined by ASABE (2007) using data from screens $\geq 1.15 \mathrm{~mm}$.

${ }^{3}$ Particle length standard deviation determined by ASABE (2007) using data from screens $\geq 1.15 \mathrm{~mm}$.

${ }^{4}$ Geometric mean particle length determined by ASABE (2007) using data from all particle fractions and assuming a mean particle length of $0.106 \mathrm{~mm}$ for particles passing through bottom screen.

${ }^{5}$ Particle length standard deviation determined by ASABE (2007) using data from all particle fractions and assuming a mean particle length of $0.106 \mathrm{~mm}$ for particles passing through the bottom screen.

concentrations decreasing in all rations after feeding to a low at about $11.5 \mathrm{~h}$ and then increasing to preprandial levels. In all rations, fecal ash concentrations followed a pattern over time similar to NDF and INDF concentrations, and fecal DM concentrations followed a pattern over time similar to starch concentrations. Neither $\mathrm{X}_{\mathrm{gm}}$ Ret nor $\mathrm{X}_{\mathrm{gm}}$ Tot (Figure 4) was affected by time after feeding; however, several individual particle size fractions did change significantly over time. The fractions that were affected by time after feeding were 0.6 and $0.15 \mathrm{~mm}$, using the retained procedure, and $0.15 \mathrm{~mm}$ and soluble, using the total procedure (data not shown). Figure 4 also shows that generally, $\mathrm{X}_{\mathrm{gm}}$ Tot decreased with increasing TMR particle size.

\section{Intakes, Fecal Output, and Digestibility}

Dry matter intakes ranged from 23.6 to $27.1 \mathrm{~kg} / \mathrm{d}$ and were not affected by treatment (Table 5). This ef- fect was also present for INDF intake and fecal output. Dry matter digestibility averaged $61.6 \%$ and decreased linearly $(P=0.08)$ as ration particle size increased. This effect was also seen by Kononoff and Heinrichs (2003b), who found that DMD decreased from 66.5 to $63.1 \%$ with increasing ration particle size. However, this effect is in contrast to observations of Kononoff and Heinrichs (2003a) and Yang and Beauchemin (2005), who found that DMD increased with increasing ration particle size. Digestibility of NDF and starch averaged 45.6 and $94.8 \%$, respectively, and neither was different among rations in the current study. Many conflicting results exist comparing changes in DMD with NDF digestibility (NDFD) and starch digestibility (StarchD) when ration particle size is increased. Some studies reported no differences in DMD, NDFD, or StarchD (Yang and Beauchemin, 2006, 2007), whereas another study reported no differences in DMD and NDFD, but StarchD decreased (Krause et al., 2002)

Table 4. Effect of feeding TMR containing short (S), medium (M), long (L), or extra long (XL) grass hay on daily weighted mean fecal particle size distribution

\begin{tabular}{lrrrrrrr}
\hline Screen, ${ }^{1} \mathrm{~mm}$ & $\mathrm{~S}$ & $\mathrm{M}$ & $\mathrm{L}$ & $\mathrm{XL}$ & $\mathrm{SE}$ & Linear & Quadratic \\
\hline $\begin{array}{l}\text { Retained, \% of DM } \\
3.35\end{array}$ & 15.7 & 17.0 & 14.9 & 15.0 & 1.55 & 0.32 & 0.53 \\
1.18 & 21.0 & 21.1 & 21.1 & 20.9 & 0.75 & 0.89 & 0.85 \\
0.6 & 13.5 & 13.1 & 13.3 & 13.5 & 0.26 & 0.71 & 0.24 \\
0.15 & 49.8 & 48.9 & 50.1 & 50.6 & 1.49 & 0.38 & 0.43 \\
Total, \% of DM & & & & & & & \\
3.35 & 7.6 & 7.8 & 6.7 & 6.8 & 0.71 & 0.12 & 0.86 \\
1.18 & 10.2 & 9.9 & 9.5 & 9.5 & 0.41 & 0.18 & 0.74 \\
0.6 & 6.5 & 6.0 & 6.0 & 6.1 & 0.18 & 0.20 & 0.16 \\
0.15 & 24.0 & 22.8 & 22.5 & 22.9 & 0.84 & 0.14 & 0.12 \\
Soluble & 51.8 & 53.5 & 55.3 & 54.7 & 0.91 & 0.02 & 0.17 \\
\hline
\end{tabular}

${ }^{1}$ Weighted means determined by calculating area under the response curve according to the trapezoidal rule (Shipley and Clark, 1972). 

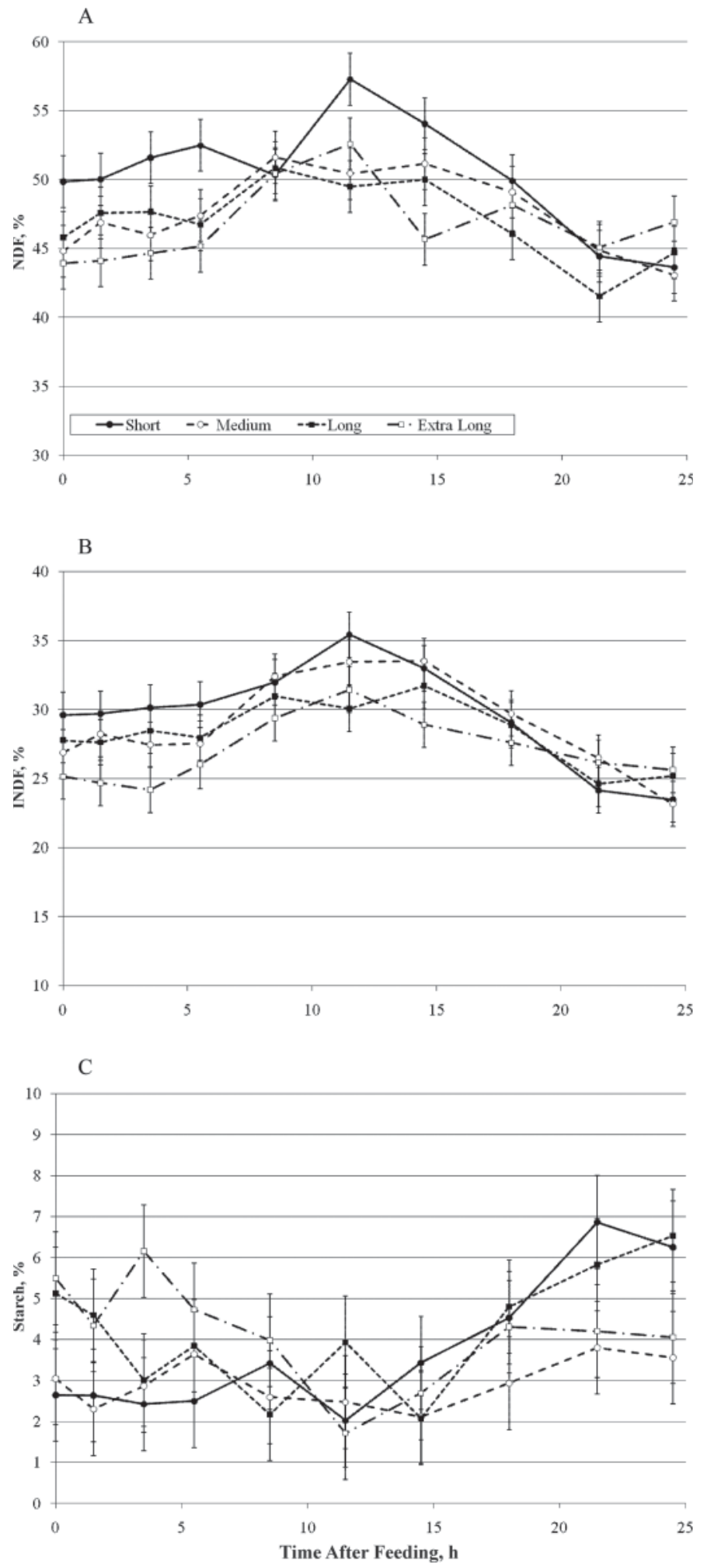

Figure 3. Effect of feeding TMR of increasing particle size on fecal NDF (A), indigestible NDF (INDF; B), and starch (C) concentration throughout the day.

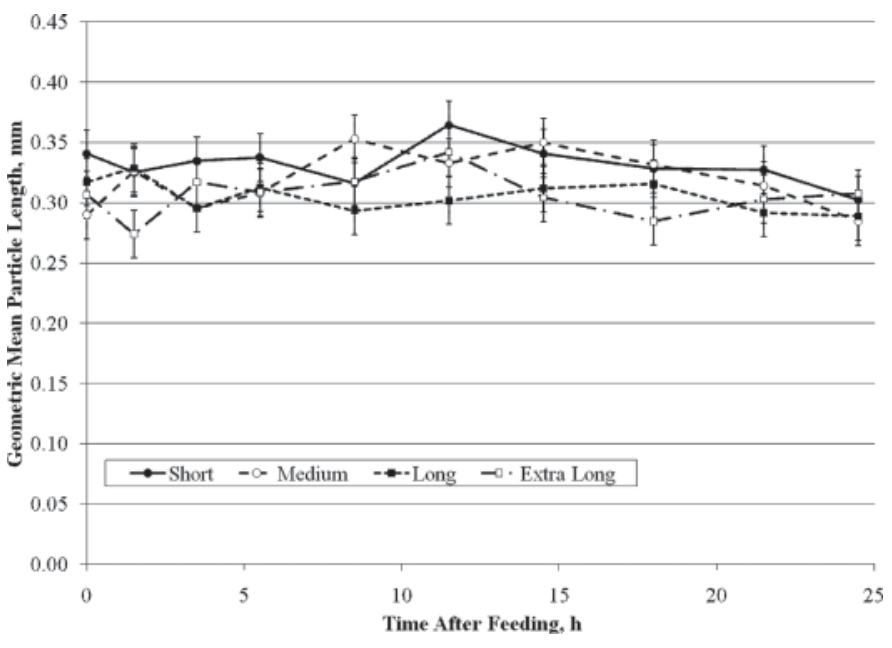

Figure 4. Effect of feeding TMR of increasing particle size on fecal geometric mean particle length (calculated using data from all particle fractions) throughout the day.

with increasing ration particle size. In addition, Yang and Beauchemin (2005) reported an increase in DMD and NDFD with no change in StarchD, but Kononoff and Heinrichs (2003a) did not see a change in NDFD with an increase in DMD (StarchD was not determined in this study) when ration particle size was increased. These differing results are likely caused by interactions between forage type, forage-to-concentrate ratio, and starch fermentability with forage particle size. None of the experiments with steam-rolled barley grain as the main starch source had any effect of ration particle size on StarchD when fed with multiple forage types (alfalfa, barley, and corn silage; Yang and Beauchemin, 2005, 2006, 2007). Only one of these studies using corn grain as the main starch source measured StarchD and it was determined that StarchD decreased with increasing ration particle size when feeding high-moisture shelled corn and dry, cracked, shell corn with alfalfa silage (Krause et al., 2002). Therefore, it seems that barley grain digestibility is independent of forage particle size, whereas corn grain digestibility may not be. Forage source did not produce consistent results for NDFD with differing ration particle size. Studies feeding an alfalfa silage-based ration had both no effect of ration particle size on NDFD (Krause et al., 2002; Yang and Beauchemin, 2007) and a decrease in NDFD with increasing ration particle size (Kononoff and Heinrichs, 2003b). Corn silage-based rations were also inconsistent, with one study having an increase in NDFD with increasing ration particle size (Yang and Beauchemin, 2005) and one study having no effect of ration particle size on NDFD (Kononoff and Heinrichs, 2003a). Many factors probably are influencing these differences in NDFD within each forage source. 
Table 5. Effect of feeding TMR containing short (S), medium (M), long (L), or extra long (XL) grass hay on DMI, indigestible NDF intake (INDFI), fecal output, and apparent digestibilities of DM, NDF, and starch

\begin{tabular}{|c|c|c|c|c|c|c|c|}
\hline Item & $\mathrm{S}$ & M & $\mathrm{L}$ & XL & SEM & Linear & Quadratic \\
\hline DMI, kg & 25.9 & 27.1 & 23.6 & 25.3 & 1.28 & 0.21 & 0.87 \\
\hline INDFI, kg & 2.8 & 3.1 & 2.5 & 2.8 & 0.17 & 0.62 & 0.74 \\
\hline Feces, kg & 9.4 & 10.7 & 8.9 & 10.3 & 0.74 & 0.27 & 0.96 \\
\hline DMD, $1 \%$ & 63.7 & 60.9 & 62.4 & 59.3 & 1.43 & 0.08 & 0.88 \\
\hline $\mathrm{NDFD}^{2} \%$ & 45.5 & 45.2 & 47.7 & 44.0 & 1.58 & 0.70 & 0.31 \\
\hline StarchD, ${ }^{3} \%$ & 95.1 & 95.7 & 94.4 & 94.0 & 0.81 & 0.22 & 0.40 \\
\hline
\end{tabular}

${ }^{1} \mathrm{DM}$ digestibility.

${ }^{2} \mathrm{NDF}$ digestibility.

${ }^{3}$ Starch digestibility.

\section{CONCLUSIONS}

In this experiment, 4 diets that varied in particle size were fed to lactating dairy cows. It was determined that rumen digesta particle size increased with increasing ration particle size for sieves $\geq 3.35 \mathrm{~mm}$ and remained the same for sieves $<3.35 \mathrm{~mm}$. Fecal particle size was not different among rations and averaged $1.13 \mathrm{~mm}$ with more than $36 \%$ of particles being retained on an $1.18-\mathrm{mm}$ sieve or larger. Therefore, it can be concluded that the critical size threshold for increased resistance to rumen escape is larger than $1.18 \mathrm{~mm}$ in modern high-producing dairy cows. In addition, this critical size is constant throughout the day as fecal particle size fractions $>1.18 \mathrm{~mm}$ were not affected by time after feeding. From this study we also concluded that for the range of TMR particle sizes fed, which was achieved using various lengths of dry grass hay, DMD tends to decrease with increasing ration particle size.

\section{ACKNOWLEDGMENTS}

This research was supported, in part, by agricultural research funds administered by The Pennsylvania Department of Agriculture Animal Health Commission (Harrisburg, PA).

\section{REFERENCES}

AOAC. 1990. Official Methods of Analysis. 15th ed. AOAC, Arlington, VA.

ASABE. 2007. Method of determining and expressing particle size of chopped forage materials by screening. ANSI/ASAE. S424.1:663665.

Evans, E. W., G. R. Pearce, J. Burnett, and S. L. Pillinger. 1973. Changes in some physical characteristics of the digesta in the reticulo-rumen of cows fed once daily. Br. J. Nutr. 29:357-376.

Kenward, M. G., and J. H. Roger. 1997. Small sample inference for fixed effects from restricted maximum likelihood. Biometrics 53:983-997.

Knudsen, K. E. B. 1997. Carbohydrate and lignin contents of plant materials used in animal feeding. Anim. Feed Sci. Technol. $67: 319-338$.
Kononoff, P. J., and A. J. Heinrichs. 2003a. The effect of corn silage particle size and cottonseed hulls on cows in early lactation. J. Dairy Sci. 86:2438-2451.

Kononoff, P. J., and A. J. Heinrichs. 2003b. The effect of reducing alfalfa haylage particle size on cows in early lactation. J. Dairy Sci. 86:1445-1457.

Kononoff, P. J., A. J. Heinrichs, and D. R. Buckmaster. 2003a. Modification of the Penn State forage and total mixed ration particle separator and the effects of moisture content on its measurements. J. Dairy Sci. 86:1858-1863.

Kononoff, P. J., A. J. Heinrichs, and H. A. Lehman. 2003b. The effect of corn silage particle size on eating behavior, chewing activities, and rumen fermentation in lactating dairy cows. J. Dairy Sci. $86: 3343-3353$.

Krause, K. M., D. K. Combs, and K. A. Beauchemin. 2002. Effects of forage particle size and grain fermentability in midlactation cows. I. Milk production and diet digestibility. J. Dairy Sci. 85:19361946.

Littell, R. C., P. R. Henry, and C. B. Ammerman. 1998. Statistical analysis of repeated measures data using SAS procedures. J. Anim. Sci. 76:1216-1231.

Maulfair, D. D., and A. J. Heinrichs. 2010. Technical note: Evaluation of procedures for analyzing ration sorting and rumen digesta particle size in dairy cows. J. Dairy Sci. 93:3784-3788.

Maulfair, D. D., G. I. Zanton, M. Fustini, and A. J. Heinrichs. 2010 Effect of feed sorting on chewing behavior, production, and rumen fermentation in lactating dairy cows. J. Dairy Sci. 93:4791-4803.

Mertens, D. R. 1997. Creating a system for meeting the fiber requirements of dairy cows. J. Dairy Sci. 80:1463-1481.

NRC. 2001. Nutrient Requirements of Dairy Cattle. 7th rev. ed. Natl. Acad. Sci., Washington, DC.

Oshita, T., K. Nonaka, S. Kume, and T. Nakui. 2004. Effects of forage type on particle size distribution of ruminal digesta and faeces of non-lactating cows fed high quality forage. Livest. Prod. Sci. 91:107-115.

Owens, F. N., and H. R. Isaacson. 1977. Ruminal microbial yields: Factors influencing synthesis and bypass. Fed. Proc. 36:198-202.

Poppi, D. P., R. E. Hendricksen, and D. J. Minson. 1985. The relative resistance to escape of leaf and stem particles from the rumen of cattle and sheep. J. Agric. Sci. (Camb.) 105:9-14.

Poppi, D. P., D. J. Minson, and J. H. Ternouth. 1981. Studies of cattle and sheep eating leaf and stem fractions of grasses. 3. The retention time in the rumen of large feed particles. Aust. J. Agric. Res. $32: 123-137$

Poppi, D. P., B. W. Norton, D. J. Minson, and R. E. Hendricksen. 1980. The validity of the critical size theory for particles leaving the rumen. J. Agric. Sci. (Camb.) 94:275-280.

Robson, D. S. 1959. A simple method for constructing orthogonal polynomials when the independent variable is unequally spaced. Biometrics 15:187-191.

SAS Institute. 2006. SAS User's Guide: Statistics. Version 9.1.3. SAS Inst. Inc., Cary, NC. 
Shipley, R. A., and R. E. Clark. 1972. Tracer Methods for In Vivo Kinetics. Academic Press, New York, NY.

Van Soest, P. J., J. B. Robertson, and B. A. Lewis. 1991. Methods for dietary fiber, neutral detergent fiber, and nonstarch polysaccharides in relation to animal nutrition. J. Dairy Sci. 74:3583-3597.

Yang, W. Z., and K. A. Beauchemin. 2005. Effects of physically effective fiber on digestion and milk production by dairy cows fed diets based on corn silage. J. Dairy Sci. 88:1090-1098.

Yang, W. Z., and K. A. Beauchemin. 2006. Increasing the physically effective fiber content of dairy cow diets may lower efficiency of feed use. J. Dairy Sci. 89:2694-2704
Yang, W. Z., and K. A. Beauchemin. 2007. Altering physically effective fiber intake through forage proportion and particle length: Digestion and milk production. J. Dairy Sci. 90:3410-3421.

Yang, W. Z., K. A. Beauchemin, and L. M. Rode. 2001. Barley processing, forage:concentrate, and forage length effects on chewing and digesta passage in lactating cows. J. Dairy Sci. 84:2709-2720. 